\title{
Astronomical education in Tajikistan. Project TAJASTRO
}

\author{
Khursandkul I. Ibadinov \& A. A. Rahmonov \\ Institute of Astrophysics of the Academy of Sciences of Tajikistan, \\ Tajik State University, Bukhoro Str. 22, 734042 Dushanbe, Tajikistan \\ email: ibadinov@mail.ru tajastro@mail.ru
}

\begin{abstract}
The centre of astronomy in Tajikistan is the Institute of Astrophysics of the Academy of Sciences of Tajikistan. This institute carries out scientific research and contributes to the preparation of the astronomical staff and to astronomical education. The reform of education in Tajikistan continues and now astronomy is studied in schools (together with physics) and at universities. The Tajik State Pedagogical University resumed in 2007 the training of teachers in physics and astronomy. Since 1999 the Tajik National University (TNU) offers a a specialty in astronomy. In 2006 is restored the Small Academy of Sciences (SAS) of Tajikistan. There is a planetarium in Khujand and in 2006 the Institute of Astrophysics, TNU and the Astronomical Society of Tajikistan, along with the support IBSP/UNESCO, organised the Training Methodical Center (TMC) "TAJASTRO" at the Hisar astronomical observatory for students, graduate students, young scientists, and teachers at secondary schools.
\end{abstract}

Keywords. Teaching, outreach

\section{Astronomical science in Tajikistan}

Astronomy has played an important rôle in the formation of civilisations. History shows that depending on the state of astronomy, it is possible to judge the level of economic, scientific, technical, intellectual and spiritual development of a country. In Tajikistan and in other countries of Central Asia, astronomy takes an important place in the culture and traditions of the people. For over 3000 years, people celebrate Navruz (nav, new, and ruz, day). Navruz is the day of Vernal equinox, the first day of the astronomical year. There is also some astronomical information present in the book of Avesta. Recently a 2500 years-old astronomical building was found in East Pamir (Bubnova \& Konovalova 2006). The achievements of astronomers of the state of Samanids, the Samarkand astronomical school is well-known (Babadzhanov 2001). Modern astronomy in Tajikistan is related to the Tajik astronomic observatory (TAO), founded in 1932 (Solovyov 1957; Dobrovol'Skij 1987; Babadzhanov 2001; Ibadinov 1993, 1997). In 1958 the observatory was included in the Institute of Astrophysics of the Academy of Sciences of Tajikistan, which has become the main centre for astronomy in Tajikistan. This institute carries out scientific research and brings an important contribution to preparation of experts in the field of astronomy, in astronomical education and outreach. There are 3 astronomical observatories, 2 Departments and 5 scientific groups within the Institute of Astrophysics:

- Hisar astronomical observatory (HisAO) near Dushanbe;

- International astronomical observatory Sanglokh in the Dangara region;

- Astronomical observatory Pamir in Murgab region of Pamir;

- Department of Comets and Asteroids with the Group of Experimental Astrophysics;

- The Department of Meteor astronomy;

- The Group of Ionosphere; 

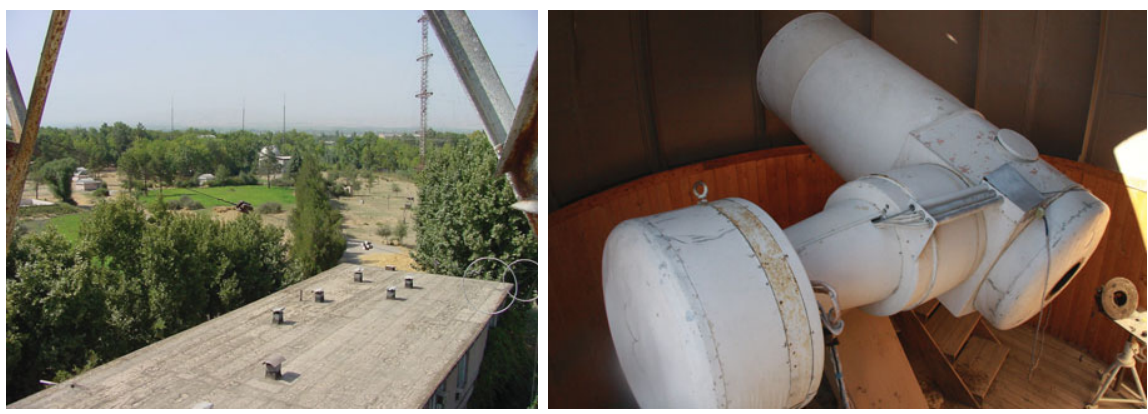

Figure 1. The astronomical observatories of Hisar (left) and Pamir (right).

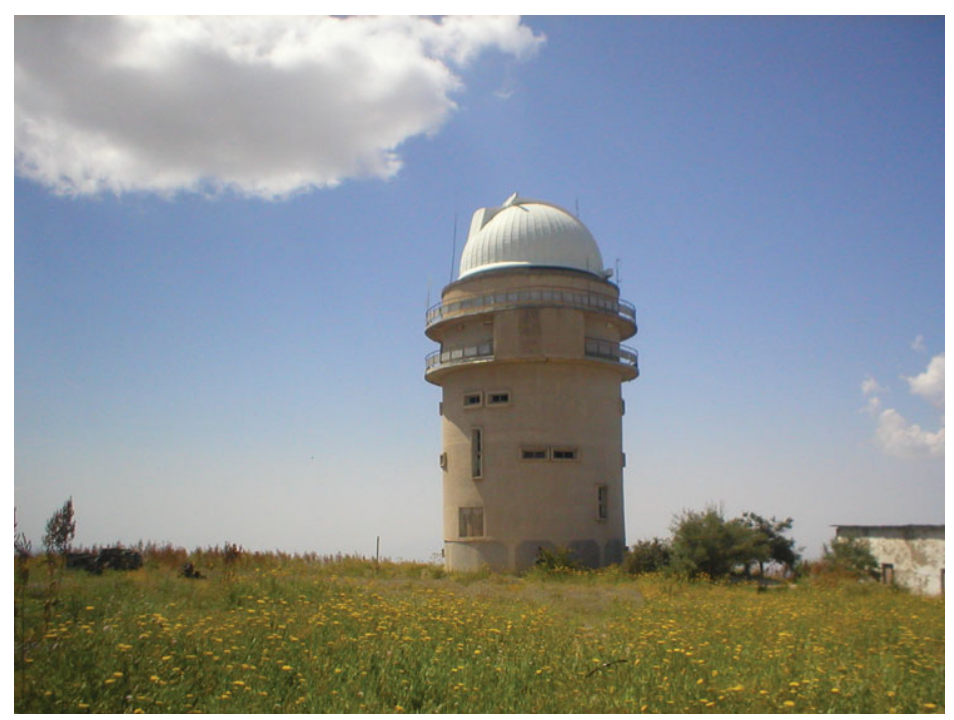

Figure 2. The astronomical observatory of Sanglokh.

Table 1. Astronomical observatories in Tajikistan

\begin{tabular}{lrrrrrr}
\hline & longitude & latitude & height $[\mathrm{m}]$ & $N$ & seeing & $P$ \\
\hline Hisar & $68^{\circ} .6$ & $38^{\circ} .5$ & 730 & 1620 & $2^{\prime \prime} 10$ & 0.72 \\
Sanglokh & $60^{\circ} 0$ & $38^{\circ} .2$ & 2300 & 1700 & $0^{\prime \prime} 54$ & 0.78 \\
Pamir & 74.0 & $38^{\circ} .0$ & 4350 & 1820 & $0^{\prime \prime} .54$ & 0.86 \\
\hline
\end{tabular}

Note: $N$ is the number of astronomical hours per year and $P$ is the optical transmission factor of the atmosphere.

- The Group of Astrometry;

- The Group of Variable stars;

- The Group of Structure and Dynamics of the Star systems.

Hisar observatory has a $1 \mathrm{~m}$ reflector, a $0.7 \mathrm{~m}$ reflector, a $0.4 \mathrm{~m}$ reflector, a $0.2 \mathrm{~m}$ refractor and mamy small photographic chambers and 3 meteor patrols, devices for radio location of meteors and ionospheric events and devices for laboratory modeling of comets. Sanglokh observatory has a $1 \mathrm{~m}$ Ritchey-Chrétien reflector, a $0.6 \mathrm{~m}$ reflector, a $0.2 \mathrm{~m}$ reflector and photographic chambers for meteor observations. Pamir observatory has a $0.7 \mathrm{~m}$ reflector, and a solar telescope. 


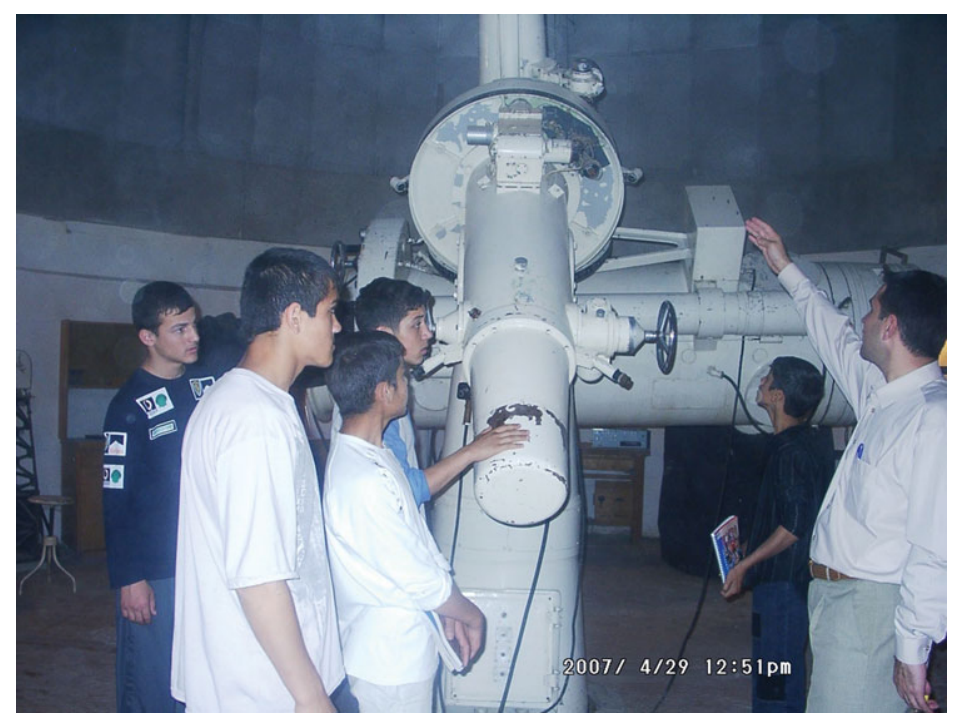

Figure 3. Pupils of the section of astrophysics of the Small Academy of Sciences (SAS) during an astronomical observation at Hisar observatory.

The main research areas at the Institute are small bodies of the solar system (comets, asteroids, meteoroids), variable stars, Galactic dynamics and structure, star formation complexes, artificial satellites and their fragments, solar-Earth connection and seismoionospheric effects.

\section{Education in astronomy}

\subsection{Astronomy in schools}

In Tajikistan the reform of education continues. The basic astronomical data on the Earth, Sun and Moon, and constellations, etc. are given to pupils of initial classes of the school in a subject Natural history. The astronomical themes have a total volume of 36 hours studied in Physics in the senior classes. In the certificate level of secondary education astronomy is not present. This creates some difficulties and certain complexities. In high schools there are no educational observatories, and in the majority of schools there are not even labs of astronomy. In our opinion the improvement of quality of teaching of astronomy in high schools requires that astronomy is studied as an independent subject and the certificate of secondary education includes astronomy.

\subsection{Astronomy and the Small Academy of Sciences}

With the purpose of bringing in capable young people in science the Academy of sciences of Tajikistan created in 2006 the Small Academy of Sciences (SAS). The section of Astrophysics operates at the Institute of Astrophysics, where students of secondary schools start their first steps in astronomy. This section now includes more than ten students of 8-10 classes of high schools of Dushanbe and nearby areas. Theoretical and practical lectures are given young scientists and post-graduate students of the Institute once a week. Pupils carry out astronomical observations at the telescopes at HisAO and seesions are organised in the Spring and Summer. The Summer sessions (two weeks) take place at the resthouse of the Academy of Sciences in the beautiful mountain gorge of Ramit. At these sessions pupils complete reports. 
Table 2. Program of the speciality in Astronomy at TNU.

\begin{tabular}{rll}
\hline \multicolumn{2}{l}{ Subjects in general courses } & Subjects in special courses \\
\hline 1 Astronomy & 1 Geophysics and physics of planets \\
2 Spherical astronomy & 2 Comets \\
3 Astrometry & 3 Asteroids \\
4 Celestial mechanics & 4 Meteors \\
5 Astrophysics & 5 Variable and non stationary stars \\
6 Practical astrophysics & 6 Galaxies \\
7 Astrophotometry & 7 Bases of cosmology \\
8 History of astronomy & 8 Modern problems of astrophysics \\
9 Method of teaching astronomy & 9 Computer technique and technology \\
10 General astronomic practice & 10 Methods of teaching astronomy \\
& & 11 Modern methods of teaching of astronomy \\
& & 12 Course on the choice of students \\
\hline
\end{tabular}

\subsection{Astronomy at universities}

In all universities of Tajikistan astronomy themes (6 hours) are studied in the subject curriculum Concepts in modern natural sciences. At faculties of physics and mathematics of seven universities, students study general astronomy within the limits of 36-72 hours. At the Tajik National University there are curricula for a specialty as "Physicist" on "Astrophysics" which involves 74 hours, while the specialty "Meteorology" includes Bases of astronomy and methods of research of space in 72 hours, plus Astrophysics bases in 36 hours. At Faculty of Mathematics 36 hours are allocated for astronomy. At the Faculty of Physics and Mathematics of the Tajik State Pedagogical University, 72 hours are allocated for astronomy. About the same quantity of hours for astronomy is allocated at the Faculties of Physics and Mathematics of the universities of the cities of Khujand, Kulob, Kurgonteppa, and Khorog. At the higher educational institutions of Tajikistan there are no educational astronomical observatories.

With a view to preparare qualified teachers of physics and astronomy for high schools, the Tajik State Pedagogical University (TSPU) set up in 2007 the specialty of "Physicsastronomy", where the specific issues of astronomical edication are presented. The teaching at comprehensive schools is improving, and textbooks on astronomy in Tajik language are prepared. The system of education strongly suffered in the years of social-political instability and civil war (1992-1997) and the economic crisis. A massive exile of specialists took place, and also many specialists-astronomers became teachers or went to work in industries. This has negatively affected astronomical research, the quality of preparation of experts and the astronomical education in Tajikistan. The Institute of Astrophysics of Academy of Sciences of Tajikistan requested the Government to set up a speciailty in Astronomy at the Tajik National University (TNU). The speciality of astronomy and the Department of Astronomy was eventually created in 1999 at the Faculty of Physics of TNU. The preparation of on-line tutorials and lectures, provided by department specialists, and ranked by equipment, by educational literature is now organised by Institute of Astrophysics of Academy of Sciences of Tajikistan. Now most astronomical subjects are studied at this speciality and the curriculum is very similar to the one at Moscow State University.

Again, the research establishment for this specialty is the Institute of Astrophysics while students pass their practical courses at the Hisar observatory and where they prepare term and diploma papers.

The reform of high education goes on in Tajikistan. Since 2007 TNU offers degrees of Bachelor (4 years) and Specialist (5 years). The Magistrate degree $(2$ years after the 


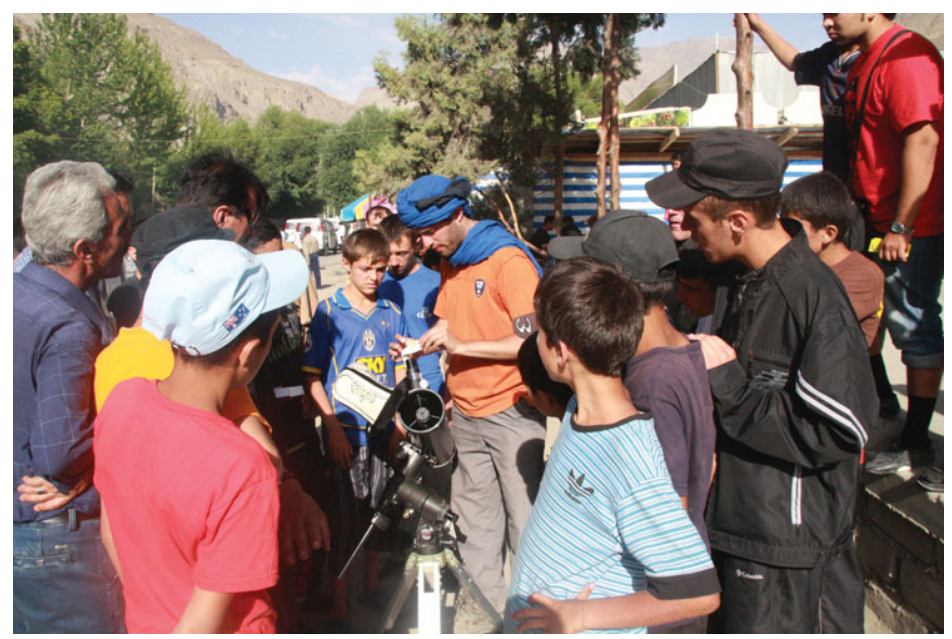

Figure 4. Observations of the solar eclipse on August 1st 2008 from in Khorog (Pamir) with the kind participation of members of Uranoscope (France).

bachelor) is also possible. A new curriculum and plan are being developed. There are problems with the level and quality of education, with the inflow of capable youth to astronomical science, etc. The Institute of Astrophysics of the Academy of Sciences of Tajikistan also offers postgraduate and doctoral studies in astronomy.

\section{Outreach activities}

The Tajik Astronomical Society and the Planetarium of the city of Khujand, along with TV, radio and newspapers are engaged in the outreach of astronomy. Mass media often mention astronomical events, and pay attention to the scientific results obtained by scientists of Tajikistan. The weekly visits to the Hisar astronomical observatory, include Tajik films on astronomical themes. Employees of Institute of Astrophysics give lectures at higher education institutions, high schools, and the public. The outreach activities have increased in connection with the International Year of Astronomy 2009.

Observations a solar eclipse 01.08.2008 in Khorog (Pamir) with participation of employees Uranoscope of France

During the International Year of Astronomy (IYA2009) in Tajikistan there were many activities, among which the convention of the Tajik Astronomical Society, the conference on physics and dynamics of small bodies of the Solar system (Dushanbe, Institute of Astrophysics, December 2009), meetings and lectures of astronomers with teachers, students and the general public, articles in newspapers, TV and radio shows, and visits to the Hisar observatory.

\section{Project Tajastro}

Under the current conditions of radical reorganisation of socio-economic and socialpolitical bases of society in Tajikistan, the system for the middle- and higher education -including astronomical education- experiences serious difficulties. One of the reasons is the religious fanaticism of part of the public with wrong or deformed notions about cosmic space and the place of humankind. With the aim of strengthening the national potential of astronomy and the training of teachers in astronomy and physics, the TNU, the Institute of Astrophysics and the Astronomical Society of Tajikistan -with support 
Table 3. The education plan of the Tajastro project

\begin{tabular}{ll}
\hline Subjects & Subjects \\
\hline Structure of universe & Use of CCD for astrophysical observations \\
Expansion of universe & Space observatories \\
Star and star system formation & Universe at other frequencies \\
New information on the solar system & Life in Universe / SETI \\
Radiation of atoms and molecules in space & Modern methods of teaching of Astronomy \\
Spectral analysis of cosmic objects & Training on telescopes \\
& Training on computers \\
\hline
\end{tabular}

IBSP/UNESCO- have organised the Training Methodical Centre (TMC) Tajastro in astronomy. TMC Tajastro aims at students and post-graduate students, teachers of astronomy of middle schools and universities, and also youngg scientists. Variations of the curriculum (40 hours) are constructed taking into account the level of preparation of participants and the specificity of their activities and include the questions connected with achievements and problems of astronomy, new methods, techniques and technology. TMC Tajastro courses take place at the Hisar astronomical observatory (HisAO) of the Institute of Astrophysics of Academy of Sciences of Republic of Tajikistan, located at 20 $\mathrm{km}$ from Dushanbe, and $730 \mathrm{~m}$ above sea level.

The Training Methodical Centre of astronomy Tajastro will be strengthening the national potential in the areas of astronomy and training of the teachers in astronomy and physics. It offers organisation, which basic problem will be the realisation of the information, resources and methodical support of schools and institutions and teachers on physics and astronomy of Tajikistan and increase of their qualification. This centre, with good financial support, can become constantly operating as training-methodical center for the countries of Central Asia.

\section{References}

Babadzhanov, P. B. 2001, in Astronomy for developing countries. Proceedings of a Special Session of the XXIV General Assembly, IAU, A. H. Batten (ed) (San Francisco: Astronomical Society of the Pacific), p. 187

Bubnova M. A. \& Konovalova, N. A. 2006, in: The Pamir Expedition (clauses and materials of field research) (Moscow: Publications of the Institute of oriental studies of the Russian Academy of Sciences), p. 170

Dobrovol'Skij, O. V. 1987, in News of the Academy of Sciences Tadjik SSR, (Dushanbe: Publ. Donish), 2, p. 3

Ibadinov, K. I. 1993, Institute of Astrophysics of the Academy of Sciences of Republic Tajikistan (Dushanbe: Polygraphist Centre No 1)

Ibadinov, K. I. 1997, in Astronomy at the sharp turns of the XXth century history (Moscow: Dubna Publ. Phoenix), p. 345

Solovyov, A. V. 1957, Bulletin of the Stalinabad Astronomical observatory, Publ. Acad. of Sci. of Tajik SSR, 22-23, 5 